Ruba J. Mohammed BDS, MSc (Lect)

Dr. Nazar Gh. Jameel BDS, MSc, PhD.(Prof)

Mohammad N Al-Mallah BDS, DDR

\section{Calibration Factor for Conventional Linear Cephalometric Measurements}

\author{
Department of Pedodontic, Orthodontic, Preventive Dentistry
}

College of Dentistry, University of Mosul

Department of Oral and maxillofacial surgery

College of Dentistry, University of Mosul

Specialized Dental Center / Nineveh Health Organization

\begin{abstract}
الخلاصة
الاهداف: من هذه الدراسة هو تحديد قيمة عامل المعايرة للقضاء على التثويه في قياسات الرأس الخطية. المواد وطرائق العمل: أجريت الدراسة

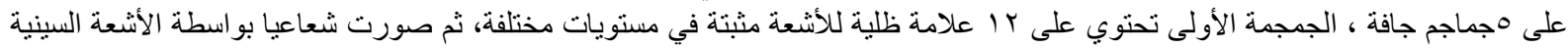

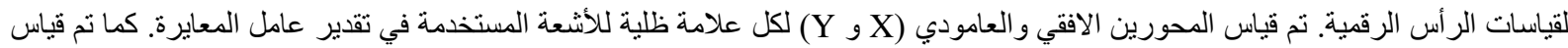

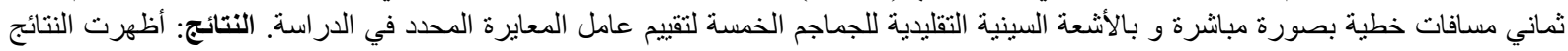

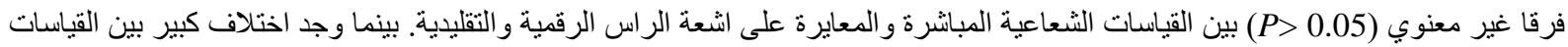

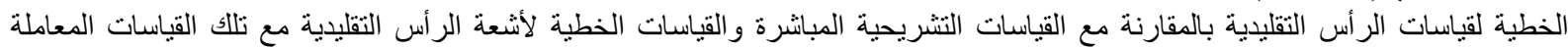

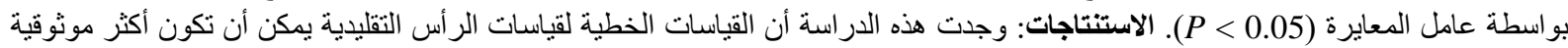

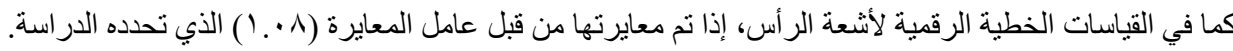

\begin{abstract}
Aims: the aim of this study is to determine a calibration factor to eliminate the distortion in the linear cephalometric measurements. Materials and Methods; the study was performed on the 5 dry skulls, the first skull contained 12 radiopaque markers fixed at different plains, and radiographed by digital cephalometric $\mathrm{x}$-ray machine. The $\mathrm{X}$ and $\mathrm{Y}$ axes of the shadow of each radiopaque marker used to estimate the calibration factor. Eight linear distances measured directly and radiographically on the conventional cephalographs of the 5 skulls to evaluate the detected calibration factor. Results; the results showed no-significant difference $(p>0.05)$ between the direct and calibrated radiographic measurement on the digital and conventional cephalographs. whereas significant difference was found between the conventional cephalometric linear measurements as compared with direct anatomical linear and the conventional cephalometric linear measurements with those measurements manipulated with the estimated calibration factor $(p<0.05)$. Conclusions; this study found that the conventional cephalometric linear measurements could be reliable as that of digital cephalometric linear measurements, if it's calibrated by the calibration factor (1.08) which is estimated by the present study.
\end{abstract}

Key words: calibration factor, digital radiograph, conventional cephalometric radiograph, linear measurements

Mohammad RJ, Jameel NGH, Al-Mallah MN. Calibration Factor for Conventional Linear Cephalometric Measurements. .Al-Rafidain Dent J. 2018,18(1):31-41.

Received: 29/4/2018 Sent to Referees: 15/5/2018 Accepted for Publication: 3/6/2018 


\section{INTRODUCTION}

Conventional cephalometric analysis, is a treatment tool as a part of the orthodontic records, it includes lateral cephalograms and represented by widely used linear and angular measurements ${ }^{1,2,3}$. Digital cephalometry is a better tool in clinical orthodontics, the cephalometric analysis, must be as comparable and reliable as it is on conventional radiographic film, which is still considered as the golden standard in contemporary orthodontics ${ }^{4,5,6}$. However, still there is variation with lateral cephalograms lead to change in the magnification and distortion especially with linear measurements ${ }^{7,8}$. Image size distortion (magnification) is the increase in size of the image on radiograph compared with actual size of the object. The divergent paths of photons in an $\mathrm{x}$-ray beam that cause an enlargement of the image on a radiograph ${ }^{9,10}$. The image distortion may be different at different parts of the $\mathrm{x}$-ray beam pathway. Thus, two or more objects may have different distortions when positioned at the locations with different distances from the image receptor ${ }^{3,11}$. The aim of this study is to determine a calibration factor used to eliminate the distortion from the linear cephalometric measurements.

\section{MATERIAL AND METHODS}

The study performed on the five dry skulls, the first skull contained 12 radiopaque markers (stainless steel balls with $3.95 \mathrm{~mm}$ diameter) fixed with soft wax to be at a different sagittal plains from the image receptor ${ }^{12,13}$ (Table - 1).

Table (1): list of radiopaque marker sites.

\begin{tabular}{cl}
\hline No. & Site of Markers \\
\hline 1 & The deepest point of the nasal bridge. \\
2 & The center of the Sella turcica. \\
3 & Anterior nasal spine. \\
4 & Posterior nasal spine. \\
5 & Midline of the mandibular symphysis. \\
6 & Mental foramen (left side). \\
7 & Crest of the alveolar ridge in lower premolar region (Left side). \\
8 & Crest of the alveolar ridge in lower $2^{\text {nd }}$ molar region (Right side). \\
9 & The external surface of the ramus opposing to the mandibular foramen (right side). \\
10 & The external surface of the ramus opposing to the mandibular foramen (left side). \\
11 & Crest of the alveolar ridge in upper premolar region (right side)*. \\
12 & Crest of the alveolar ridge in upper premolar region (left side)*. \\
\hline & * excluded value.
\end{tabular}


The skull fixed and masked with elastic transparent bandage on the cephalostate of Planmeca Dimaxis Pro x-ray machine Finland (Figure -1; A), which operated at 8 $\mathrm{mA}, 78 \mathrm{kVp}$, and $23 \mathrm{sec}$. scanning time. The digital cephalometric images stored in the

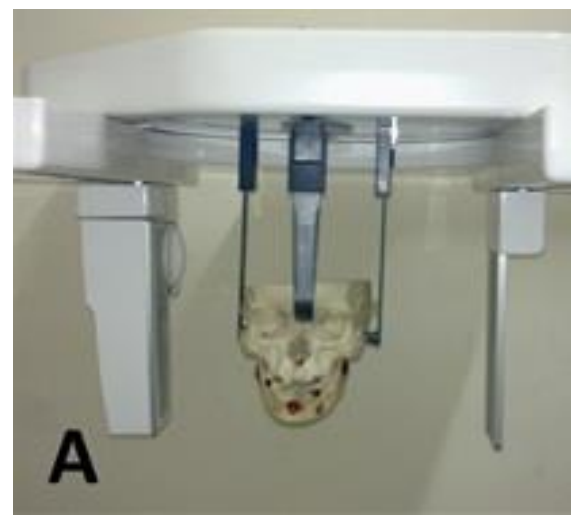

data base as TIFF format (tagged image file format). The $\mathrm{X}$ and $\mathrm{Y}$ axes of the shadow of each radiopaque marker (stainless steel balls) were measured twice by Dimaxis classic imaging software (Figure -1; B).

Figure (1): A- Positioning of skull containing metallic markers on the cephalostat. BCephalometric radiograph of skull showing the radiopaque markers.

According to the manufacturer instruction, the first measurements were calibrated by using the plastic stopper of the cephalostate containing a measuring strap to define a reference distance to calibrate the linear measurements and to remove any magnification resulted from geometric factor. While, the second measurements are taken without calibration. The magnification factor was calculated by a formula used to calculates the magnification rate $^{14}$;

\section{The magnification rate $=$ radiographic object length / actual object length.}

The magnification factor calculated by dividing the non-calibrated radiographic

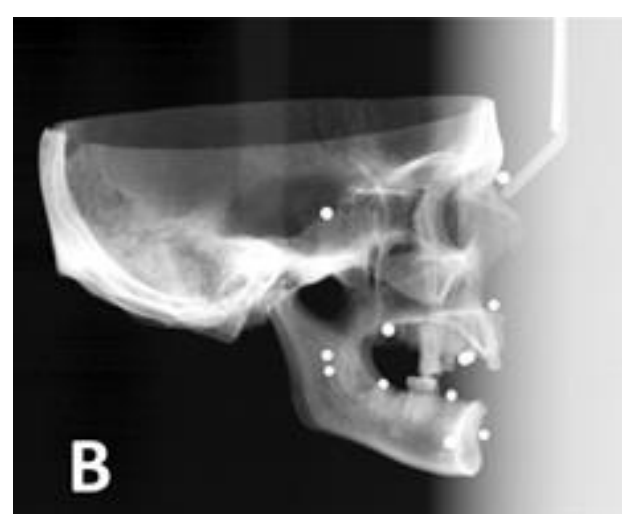

measurements to the direct diameter of metallic balls. The mean value approximated to the nearest part of hundreds of millimeter which is equal to (1.08). Two radiopaque markers in the right and left upper premolar regions were excluded due to the superimposing of radiographic shadows on both sides.

Eight linear distances (N-ANS, ANSMe, ANS-PNS, A-Pog, A-B, Ramus width, Go-Co, and Go-Me) connect cephalometric anatomical landmarks (Tables 2 \& 3 ) measured directly on the five skulls by using a high-precision digital caliper calibrated to the nearest $0.01 \mathrm{~mm}$ (Figure 2) to be used as standard measurements ${ }^{12,15}$. Conventional 
cephalometric radiographs were taken for the five skulls with conventional cephalometric $\mathrm{x}$-ray machine, type STRATO-M 505, model-2000, Italy which operated at $78 \mathrm{kVp}, 8 \mathrm{~mA}$ and $0.8 \mathrm{sec}$. of exposure time. All the exposed radiographic films were processed manually in the darkroom at the room temperature (Figure $3)$.

Table (2): definition of the cephalometric landmarks.

\begin{tabular}{|c|c|c|}
\hline No. & Landmarks & Definition \\
\hline 1 & $\mathrm{~N}$-point & $\begin{array}{l}\text { (Nasion): The most anterior point of the nasofrontal suture in the mid- } \\
\text { sagittal plain }{ }^{17} \text {. }\end{array}$ \\
\hline 2 & ANS & $\begin{array}{l}\text { Anterior Nasal Spine): The anterior tip of the sharp bony process of the } \\
\text { maxilla }{ }^{18} \text {. }\end{array}$ \\
\hline 3 & PNS & $\begin{array}{l}\text { (Posterior Nasal Spine): The posterior spine of the palatine bone } \\
\text { consisting of the hard palate which coincides with the lowest point of } \\
\text { the pterygomaxillary fissure (ptm) }{ }^{19} \text {. }\end{array}$ \\
\hline 4 & Me -point & $\begin{array}{l}\text { (Menton): The lowest point on the symphyseal shadow of the mandible } \\
\text { is seen on the lateral cephalogram } \\
20\end{array}$ \\
\hline 5 & Go - point & $\begin{array}{l}\text { (Gonion): A midpoint of the angle of the mandible found by bisecting } \\
\text { the angle formed by the mandibular and ramus plain }{ }^{21} \text {. }\end{array}$ \\
\hline 6 & Co -point & (Condylion): most superior point of head of condyle ${ }^{22}$. \\
\hline 7 & A -point & $\begin{array}{l}\text { (Subspinale): The most posterior midline point overlying upper central } \\
\text { incisors root apex in the concavity between the anterior nasal spine }{ }^{22} \text {. }\end{array}$ \\
\hline 8 & B -point & $\begin{array}{l}\text { (Supramentale): The most posterior point in the outer contour of the } \\
\text { mandibular alveolar process }{ }^{22} \text {. }\end{array}$ \\
\hline 9 & Pog -point & (Pogonion): The most anterior point on the bony $\operatorname{chin}^{23}$. \\
\hline
\end{tabular}

Table (3): definition of the cephalometric linear distances.

\begin{tabular}{cll}
\hline No. & Linear distance & Definition \\
\hline 1 & N-ANS & Nasion - Anterior nasal spine. \\
2 & ANS-Me & Anterior nasal spine - Menton. \\
3 & ANS-PNS & Distance between the anterior \& posterior nasal spines. \\
4 & A-Pog & Distance from A-point to Pogonion. \\
5 & A-B & Distance between the A \& B - points \\
6 & Ramus width & Deepest points of the anterior \& posterior aspects of the \\
7 & Go-Co & ascending Ramus. \\
8 & Go-Me & Gonion - Condylon (Ramus height) \\
\hline
\end{tabular}




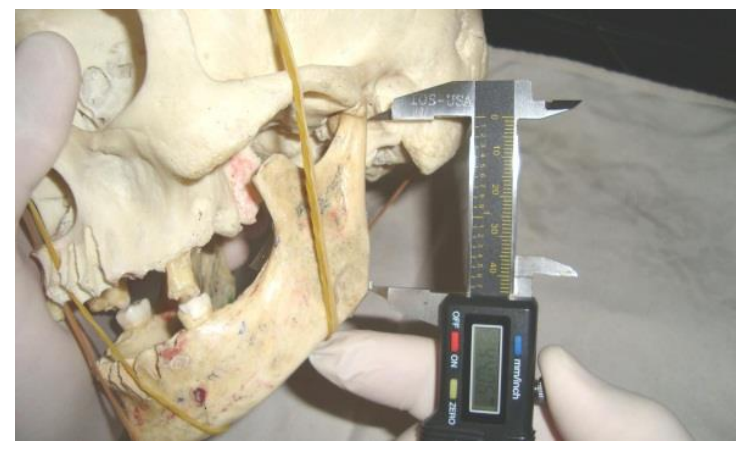

Figure (2): direct measurement of linear distances.

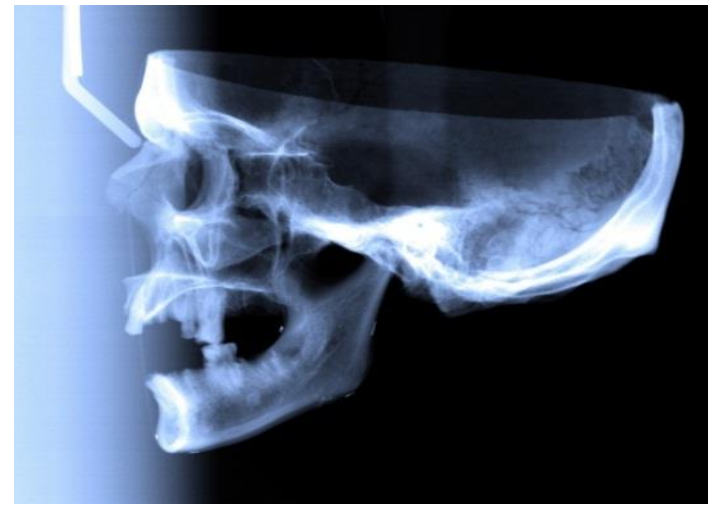

Figure (3): conventional cephalometric radiograph.

The same linear distance measured radiographically with conventional manual tracing $^{16}$. The conventional radiographic linear measurements were divided by the estimated calibration factor (1.08), for additional evaluation. Then, the obtained direct conventional linear cephalometric measurements were compared with direct and calibrated linear cephalometric measurements. Statistical analysis; the data analyzed statistically with the paired sample $t$-test by SPSS software version 11.5.

\section{RESULTS}

The results showed a non-significant difference $(p>0.05)$ between the direct measurements diameters of radiopaque markers when compared with digitally calibrated radiographic measurement of their diameter in the $\mathrm{X}$ and $\mathrm{Y}$ axes $(p=0.270$ and 0.413$)$, and the calculated measurement of diameters by the using the defined calibration factor ( $p=$ 0.617 and 0.792). While, significant differences $(p<0.05)$ was found when compare the non-calibrated digital radiographic measurement of the markers diameters in $\mathrm{X}$ and $\mathrm{Y}$ axes with direct, calibrated radiographic and calculated radiographic measurements by the calibration factor $(p=0.000)$ (Table 4$)$. 
Table (4): comparison of the direct diameter measurement of radiopaque markers with other radiographic measurements methods in $\mathrm{X} \& \mathrm{Y}$ axes.

\begin{tabular}{ccccccc}
\hline \multirow{2}{*}{ Group } & Pairs & Group & $\begin{array}{c}\text { Mean } \\
\text { diff. }\end{array}$ & SD & $t$-value & $P$-value \\
\hline \multirow{4}{*}{$\mathrm{X}$} & 1 & Direct -calibrated & 0.025 & 0.0672 & 1.176 & 0.270 \\
& 2 & Direct - noncalibrated & -0.379 & 0.0152 & -78.648 & 0.000 \\
& 3 & Direct - factor & -0.007 & 0.0427 & -0.518 & 0.617 \\
& 4 & calibrated-noncalibrated & -0.404 & 0.0724 & -17.634 & 0.000 \\
& 5 & Calibrated- factor & -0.032 & 0.0882 & -1.146 & 0.281 \\
& 6 & Noncalibrated- factor & 0.372 & 0.0473 & 24.855 & 0.000 \\
& 1 & Direct -calibrated & 0.009 & 0.0331 & 0.859 & 0.413 \\
$\mathrm{Y}$ & 2 & Direct - noncalibrated & -0.354 & 0.0503 & -22.222 & 0.000 \\
& 3 & Direct - factor & -0.003 & 0.0349 & -0.271 & 0.792 \\
& 4 & calibrated-noncalibrated & -0.363 & 0.0539 & -21.271 & 0.000 \\
& 5 & Calibrated- factor & -0.012 & 0.0523 & -0.712 & 0.494 \\
& 6 & Noncalibrated- factor & 0.351 & 0.0474 & 23.377 & 0.000 \\
\hline
\end{tabular}

A significant difference was found between the direct anatomical linear and conventional cephalometric linear measurements. The same significant was found when compare the conventional cephalometric linear measurements with those measurements manipulated with the estimated calibration factor $(p<0.05)$ (Table 5). While, the comparison between direct and the calibrated linear cephalometric measurements was not significant $(p>0.05)$ (Table 5).

Table (5): comparison of the direct linear anatomical distances measurement with noncalibrated and calibrated conventional cephalometric measurements methods.

\begin{tabular}{clccccc}
\hline & Group & No. & $\begin{array}{c}\text { Mean } \\
\text { diff. }\end{array}$ & S.D & $t$-value & $P$-value \\
\hline \multirow{3}{*}{ N-ANS } & Direct - Noncalib & 5 & -3.830 & 0.2090 & -40.968 & 0.000 \\
& Direct - Factor & 5 & -0.130 & 0.1977 & -1.470 & 0.215 \\
& Noncalib - Factor & 5 & 3.700 & 0.2230 & 37.093 & 0.000 \\
& Direct - Noncalib & 5 & -3.512 & 0.5375 & -14.609 & 0.000 \\
ANS-Me & Direct - Factor & 5 & 0.348 & 0.9625 & 0.808 & 0.464 \\
& Noncalib - Factor & 5 & 3.860 & 0.7684 & 11.232 & 0.000 \\
Ramus & Direct - Noncalib & 5 & -4.062 & 0.4347 & -20.892 & 0.000 \\
width & Direct - Factor & 5 & -0.306 & 0.5465 & -1.252 & 0.279 \\
& Noncalib - Factor & 5 & 3.756 & 0.8520 & 9.857 & 0.001 \\
Go-Co & Direct - Noncalib & 5 & -3.122 & 0.2728 & -25.590 & 0.000 \\
& Direct - Factor & 5 & -0.002 & 0.1229 & -0.036 & 0.973 \\
ANS- & Noncalib - Factor & 5 & 3.120 & 0.3727 & 18.716 & 0.000 \\
& Direct - Noncalib & 5 & -2.978 & 0.0491 & -135.36 & 0.000 \\
\hline
\end{tabular}




\begin{tabular}{ccccccc}
\hline PNS & Direct - Factor & 5 & 0.018 & 0.1308 & 0.308 & 0.774 \\
& Noncalib - Factor & 5 & 2.996 & 0.1451 & 46.141 & 0.000 \\
& Direct - Noncalib & 5 & -2.754 & 0.4331 & -14.219 & 0.000 \\
A-Pog & Direct - Factor & 5 & 0.250 & 0.5719 & 0.977 & 0.384 \\
& Noncalib - Factor & 5 & 3.004 & 0.7060 & 9.513 & 0.001 \\
& Direct - Noncalib & 5 & -3.294 & 0.4440 & -16.587 & 0.000 \\
A-B & Direct - Factor & 5 & -0.068 & 0.1616 & -0.0941 & 0.400 \\
& Noncalib - Factor & 5 & 3.226 & 0.4085 & 17.658 & 0.000 \\
& Direct - Noncalib & 5 & -3.500 & 0.5000 & -15.652 & 0.000 \\
Go-Me & Direct Factor & 5 & 0.198 & 0.5441 & 0.814 & 0.462 \\
& Noncalib - Factor & 5 & 3.698 & 0.7096 & 11.652 & 0.000 \\
\hline
\end{tabular}

\section{DISCUSSION}

In clinical orthodontics, cephalometric analysis has long been used as an important clinical tool in diagnosis, treatment planning, and evaluation of growth or treatment results ${ }^{4}$. The dry skulls used in this study because the radiographs are taken lead to superior results compared to the clinical situation for reasons of standardization of exposure technique, keeping the same relation of the object to the image receptor and $\mathrm{x}$-ray beam and obtain real direct measurements of the examined site ${ }^{15,24}$. In addition, the exposing human being to ionizing radiation for experimental study is a quite refuseable technique ${ }^{25,26}$. The metallic balls are preferred to be used as a radiopaque markers because the radiographic image of a metal ball has not been influenced by the geometrical conditions and parameters associated with an exposure (projection geometry) due to the symmetrical shape of the sphere ${ }^{13,27,28}$. Because, the magnification is not constant for all possible sagittal plains of the object, where, the structures located closer to the image receptor will present lower magnification comparing to those closer to the rays. Therefore, the markers fixed at a different sagittal plains from the image receptor $^{29}$. There is still a magnification with lateral cephalograms lead to the variation in magnification especially with linear measurements $^{7,8}$. In the present study the calibrated digital linear measurements show non-significant difference with direct linear measurements. While, the conventional linear cephalometric measurements showed a significant difference as compared with those direct measurements, these findings supported by the studies ${ }^{30,31,32,33}$ of Gayatri et $a l ., ; \quad$ Agrawal et al.,; Salman and Muhammad; and Tanwani et al.,. This significance between the conventional and direct linear measurements was reduced by the use to estimated calibration factor (1.08) to eliminate the linear image magnification. This come in agreement with Zecca et al. ${ }^{34}$; and Kamath and $\operatorname{Arun}^{35}$ studies; they showed that magnification values reported by the manufacturer might not correspond to the calculated magnification values in the different sagittal plains. In controversy, the other studies showed that the linear measurements gained by digital lateral cephalometric radiographies, were comparable to non-calibrated linear measurements obtained from conventional radiographies ${ }^{36,37,38}$.

In a study by Spolyar, ${ }^{39}$ observed a mean linear change of $1.7 \mathrm{~mm}$ ranging from 0.5 to $6.2 \mathrm{~mm}$. According to Weems ${ }^{40}$ magnification of craniofacial structures varies from almost $0 \%$ up to $24 \%$ in objects 
close to the film or objects in the exact center of the rays, where the manual conventional cephalometric linear measurements were used directly without calibration. This magnification is not constant for all possible sagittal plain of patient. Structures located closer to the film presented lower magnification comparing to those closer to the rays. Therefore, the use of estimated calibration factor makes the manual conventional cephalometric linear measurements reliable as that obtained from digital measurements by reduce or eliminate the inherent rate of linear magnification. Where, the advanced digital imaging modalities are required machine with specified software that are readily still limited to large town centers making the admittance to this technology is quite limited for most of the dental practices. In addition to the high cost of examinations, and the need of expert staff for interpretation of complex images, lead to select a clinical planning based on conventional radiographic images $^{41,42,43}$. In addition to that the radiographic film it is quite stable and can retain information for many years, due to its physical nature ${ }^{7,8}$. Thus hand-traced cephalometric analysis on traditional radiographic images have been for many years as the gold standard for analyzing a cephalometric radiograph and collecting cephalometric values $^{44,45}$. This facilitates the use of conventional cephalometric radiograph from the old patients archiving in the longitudinal studies.

\section{CONCLUSION}

The present study finds that the conventional cephalometric linear measurements could be accurate as that of digital cephalometric linear measurements, if it's calibrated by the calibration factor
(1.08) which is estimated by the present study.

\section{REFERENCES}

1. Shaw K, McIntyre G, Mossey P, Menhinick A, Thomson D. Validation of conventional 2D lateral cephalometry using 3D cone beam CT. J Orthod. 2013; 40:22-8.

2. Farronato G, Sara S, Francesca N, Alessandro Z, Farronato D. Assessment of inter- and intra-operator cephalometric tracings on cone beam CT radiographs: comparison of the precision of the cone beam CT versus the latero-lateral radiograph tracing. Progress in Orthodontics. 2014; 15:1.

3. Rayapudi N, Challa P, Gandikota CS, Yudhistar PV, Tircoveluri S. A comparative study of linear measurements of facial skeleton using computed tomography and traditional cephalometry. APOS Trends Orthod. 2013; 3:23-30.

4. Kasinathan G, Kumar S, Kommi PB, Hanumanth SS. Reliability in Landmark Plotting between Manual and Computerized Method - A Cephalometric Study. Int J Sci Stud. 2017; 4(12): 73-78.

5. Nikneshan S, Mohseni S, Nouri M, Hadian $\mathrm{H}$, and Kharazifard MJ. The Effect of Emboss Enhancement on Reliability of Landmark Identification in Digital Lateral Cephalometric Images. Iran J Radiol. 2015; 12(2): e19302.

6. Shaheed S, Iftikhar Y, Rasool G, and Bashir U. Accuracy of Linear Cephalometric Measurements with Scanned Lateral Cephalograms. Pakistan Oral Dental J.. 2011; 31(1): 68-72.

7. Bruno FG, Marcos NG, Diogo CF, James AM, Flavio RM. Accuracy and reliability of 
craniometric measurements on lateral cephalometry and 3D measurements on CBCT scans. Angle Orthod. 2011; 81:2837.

8. Navarro R, Oltramari-Navarro PV, Fernandes TM, Oliveira GF, Conti AC, Almeida MR. Comparison of manual, digital and lateral CBCT cephalometric analyses. J Appl. Oral Sci. 2013; 21(2):167-76.

9. Lindner C, Wang Ch, Huang Ch, Li Ch, Chang S and Cootes TF. Fully Automatic System for Accurate Localizations and Analysis of Cephalometric Landmarks in Lateral Cephalograms. 2016; Sci. Rep. 6. 33581; doi: 10.1038/srep33581.

10. Szuhanek C, Nagib R, Paraschivescu E, Bratu DC, Brad S, and Malita D. Digital facial and cephalometric analysis in the orthodontic treatment of a class III high angle patient: a case report. Inter Bio Biomed Eng. 2015; 9: 109-113.

11. Anuwongnukroh N, Dechkunakorn S, Damrongsri S, Nilwarat C, Pudpong N, Radomsutthisarn $\mathrm{W}$ and Kangern $\mathrm{S}$. Accuracy of Automatic Cephalometric Software on Landmark Identification. Mater Sci Eng. 2017; 265: 1-6.

12. Gandikota CS, Rayapudi N, Challa PL, Juvvadi SR, Yudhister PV. and Rao G.H. A comparative study of linear measurements on skeletal with frontal and lateral cephalogram. Contemp. Clin. Dent. 2012; 3(2): 176-179.

13. Gaddam R, Shashikumar HC, Lokesh NK, Suma T, Arya S, Shwetha GS. Assessment of Image Distortion from Head Rotation in Lateral Cephalometry. J. Intern. Oral Health. 2015; 7(6):1-6.
14. Kim YK, Park JY, Kim SG, Kim JS, Kim JD. Magnification Rate of Digital Panoramic Radiographs and Its Effectiveness for Pre-operative Assessment of Dental Implants. Dentomaxillofac Radiol. 2011; 40: 76-83.

15. Baumgaertel S, Palomo JM, Palomo L, and Hans MG. Reliability and Accuracy of Cone-Beam Computed Tomography Dental Measurements. Am J Orthod Dentofacial Orthop. 2009; 136(1):19-28.

16. Ana PR, Aline M, Pisha P, Napat B, Afonso PF, Reinhilde J. Cephalometric landmark variability among orthodontists and Dentomaxillofacial radiologists: a comparative study. Imaging Sci Dent. 2015; 45: 213-20.

17. Björk A. Cranial Base Development. Am J Orthod. 1955; 41: $198-205$.

18. Lande MJ. Growth behavior of the human bony facial profile as revealed by serial cephalometric Roentgenology. Am J Orthod. 1952; 22(2): 78 - 90 .

19. Houston WJ. Walther's Orthodontic Notes. 4th ed, John Wright and Sons. Bristol. 1983; Pp. 5 - 10, 20.

20. Graber TM. Implementation of the Roentgenographic cephalometric technique. Am J Orthod. 1958; 44(12): 906 $-932$.

21. Enlow DH. Handbook of Facial Growth. 2nd ed. Philadelphia, WB SAUNDERS Co. 1982; Pp: 297-302, 332-333.

22. Downs BW. Variation in Facial Relationships: Their Significance in Treatment and Prognosis. Am. J. Orthod. 1948; 34: 812-840. 
23. Lande MJ. Growth behavior of the human bony facial profile as revealed by serial cephalometric Roentgenology. Am. J. Orthod. 1952; 22(2): 78 - 90.

24. Zecca PA, Fastuca R, Beretta M, Caprioglio A, and Macchi A. Correlation Assessment between Three-Dimensional Facial Soft Tissue Scan and Lateral Cephalometric Radiography in Orthodontic Diagnosis. Inter J Dent. 2016; 1-8.

25. Aslani F, Feizbakhsh M, Omrani A R, Ghaffari R. Determining the Degree of Identification Differences of Anatomical Landmarks by Digital Cephalometric Radiography and Conventional Radiographic Technique Using Manual Tracing of Human Skulls. Biotech Health Sci. 2014 ;1(2): e22089.

26. Langlois de Oliveira C, Sampaio C. Maria, Silva E. Alexandre, Nilza PC, Rockenbach I. Maria. Accuracy of Linear Measurements Before and After Digitizing Periapical and Panoramic Radiography Images. Braz. Dent. J. 2011; 22(5): 404-409.

27. Schropp L, Stavropoulos A, Gotfredsen E, and Wenzel A. Calibration of Radiographs by a Reference Metal Ball Affects Preoperative Selection of Implant Size. Clin Oral Invest. 2009; 13:375-381.

28. Berketa WJ, Hirsch SR, Higgins D, James H. Radiographic Recognition of Dental Implants as an Aid to Identifying the Deceased. J Forensic Sc. 2010; 55 (1): 6670.

29. Rino Neto J, Paiva JB, Queiroz GV, Attizzani MF, Miasiro Junior H. Evaluation of radiographic magnification in lateral cephalograms obtained with different X-ray devices: Experimental study in human dry skull. Dental Press J Orthod. 2013; 18(2):17.e1-7.

30. Gayatri G, Harsanti A, Zenab Y, Rahmat I. Steiner cephalometric analysis discrepancies between conventional and digital methods using CephNinja application software. Padjadjaran J Dent. 2016: 28(3):148-152.

31. Agrawal MS, Agrawal JM, Patni V, and Nanjannawar L. An evaluation of the reproducibility of landmark identification in traditional versus computer-assisted digital cephalometric analysis system. APOS Trends Orthod. 2015. 5(3):103-110.

32. Salman Kh A. and Muhammad RJ. Comparison of lateral cephalometric analysis among the conventional, digital and hardcopy cephalographs. Al-Raf. Dent. J. 2012; 12(1): 80-88.

33. Tanwani HB, Potnis SS, Baralay SS, Patil SS. Comparison of conventional and digital cephalometric analysis: A pilot study. J Dent Allied Sci 2014; 3:80-4.

34. Zecca PA, Fastuca R, Beretta M, Caprioglio A, and Macchi A. Correlation Assessment between Three-Dimensional Facial Soft Tissue Scan and Lateral Cephalometric Radiography in Orthodontic Diagnosis. Inter J Dent. 2016; $1-8$.

35. Kamath MK, Arun AV. Comparison of cephalometric readings between manual tracing and digital software tracing: A pilot study. Int J Orthod Rehabil 2016: 7(4):135-138.

36. Rianti RA, Priaminiarti $M$ and Syahraini SI. Tolerance of image enhancement brightness and contrast in lateral cephalometric digital radiography for 
Steiner analysis. The $1^{\text {st }}$ Physics and Technologies in Medicine and Dentistry Symposium. J of Physics: Conf. Series. 2017: Pp.1-8.

37. Paixão MB, Márcio CS, Carlos JV, Telma MA. Comparative study between manual and digital cephalometric tracing using Dolphin Imaging software with lateral radiographs. Dental Press J. Orthod. 2010; 15(6):123-30.

38. Silva JMG, Castilho JCM, Matsui RH, Matsui MY, Gomes MF. Comparative study between conventional and digital radiography in cephalometric analysis. J. Health Sci. Inst. 2011; 29(1):19-22.

39. Spolyar JL. Head positioning error in cephalometric radiography - an implant study. Angle Orthod. 1987; 57(1):77-88.

40. Weems RA. Radiographic cephalometric technique. In: Jacobson A. Radiographic cephalometry from basics to video imaging. Carol Stream: Quintessence; 1995. 39-52.

41. Kumar MA, Mody B, Nair R, Gopa K, Surender LR, Gopal SS, and Prasad KA. Dimensional Accuracy and Details of the Panoramic Cross-sectional Tomographic
Images: An in vitro Study. J Contemp Dent Pract. 2012; 13(1):85-97.

42. Vilhjálmsson HV, Klock SK, Størksen K, Bardsen A. Radiological Evaluation of Single Implants in Maxillary Anterior Sites with Special Emphasis on their Relation to Adjacent Teeth - A 3-Year Follow-Up Study. Dent Traumatol. 2013; 29: 66-72.

43. White CS, Pharoah MJ. Oral Radiology: Principles and Interpretation. 7th ed. Ch.3. Safety and Protection. 2014; Pp. 29-40. Mosby. St. Louis.

44. Ahamed ST, Peddu R, Bandaru SK, Mallavarapu K, Adusumilli SP, Reddy S. Comparison of measurements from conventional, scanned, and photographed lateral cephalograms: An in vitro study. J NTR Univ. Health Sci. 2013; 2:261-8.

45. Khan SQ, Sobia AH, Mehdi H, and Ashraf B. Quality Assessment Of Lateral Cephalometric Radiographs. Pak Oral Dent J. 2017: 37(2):265-268. 